Article

\title{
An Experimental Investigation of Water Vapor Condensation from Biofuel Flue Gas in a Model of Condenser, (1) Base Case: Local Heat Transfer without Water Injection
}

\author{
Robertas Poškas *, Arūnas Sirvydas, Vladislavas Kulkovas and Povilas Poškas
}

check for

updates

Citation: Poškas, R.; Sirvydas, A.; Kulkovas, V.; Poškas, P. An

Experimental Investigation of Water

Vapor Condensation from Biofuel

Flue Gas in a Model of Condenser, (1) Base Case: Local Heat Transfer without Water Injection. Processes 2021, 9, 844. https://doi.org/10.3390/ pr9050844

Academic Editor: Francesca Raganati

Received: 9 April 2021

Accepted: 10 May 2021

Published: 12 May 2021

Publisher's Note: MDPI stays neutral with regard to jurisdictional claims in published maps and institutional affiliations.

Copyright: (c) 2021 by the authors. Licensee MDPI, Basel, Switzerland. This article is an open access article distributed under the terms and conditions of the Creative Commons Attribution (CC BY) license (https:/ / creativecommons.org/licenses/by/ $4.0 /)$.
Nuclear Engineering Laboratory, Lithuanian Energy Institute, Breslaujos 3, LT-44403 Kaunas, Lithuania; Arunas.Sirvydas@lei.lt (A.S.); Vladislavas.Kulkovas@lei.lt (V.K.); Povilas.Poskas@lei.lt (P.P.)

* Correspondence: Robertas.Poskas@lei.lt; Tel.: +370-37401893

\begin{abstract}
Waste heat recovery from flue gas based on water vapor condensation is an important issue as the waste heat recovery significantly increases the efficiency of the thermal power units. General principles for designing of this type of heat exchangers are known rather well; however, investigations of the local characteristics necessary for the optimization of those heat exchangers are very limited. Investigations of water vapor condensation from biofuel flue gas in the model of a vertical condensing heat exchanger were performed without and with water injection into a calorimetric tube. During the base-case investigations, no water was injected into the calorimetric tube. The results showed that the humidity and the temperature of inlet flue gas have a significant effect on the local and average heat transfer. For some regimes, the initial part of the condensing heat exchanger was not effective in terms of heat transfer because there the flue gas was cooled by convection until its temperature reached the dew point temperature. The results also showed that, at higher Reynolds numbers, there was an increase in the length of the convection prevailing region. After that region, a sudden increase was observed in heat transfer due to water vapor condensation.
\end{abstract}

Keywords: waste heat; condensation; experiments; vertical tube; biofuel flue gas; local heat transfer; condensation efficiency

\section{Introduction}

The water vapor condensation process is important for many industrial applications, such as nuclear, chemical, and thermal. To increase the efficiency of thermal power and boiler stations, they are equipped with condensing heat exchangers (economizers). The design of condensing heat exchangers depends on the power required [1]. Despite of that, most condensing heat exchangers have housing where a few hundreds of small diameter tubes are installed and the relative length $\mathrm{x} / \mathrm{d}$ of these tubes could be more than 150 . The flue gas from the boiler is routed to these tubes, cooling water flows around them, and a counter-current flow arrangement is usually used.

As the flue gas leaving the boiler is still of high temperature and humidity, especially when incinerating biofuel, there is a possibility to gain additional heat and increase the efficiency of boiler stations by condensing water vapor from flue gas in condensing heat exchangers. When the dew point is reached, water vapor from flue gas starts to condensate. The condensation process generates an additional amount of heat, which is usually used to heat the return water from consumers. Besides, when the condensate film flows down the condenser tubes, it precipitates various solid particles from the flue gas that are the most significant source of environmental pollution, especially when incinerating biofuels [2,3] Although the efficiency of boilers is usually less than $100 \%$, it can be increased by installing condensing heat exchangers in boilers, as condensing heat exchangers can get additional amount of heat from the same amount of burned fuel $[4,5]$.

Despite the fact that the general principles for the designing of this type of heat exchangers are known, not much knowledge is acquired of processes taking place in 
condensing heat exchangers and peculiarities of these processes in the case of flue gas. The review of publications showed that there are many experimental and theoretical studies related to pure water vapor condensation in tubes at a high condensable gas-water vapor content (90-100\%, by volume) and small amount of non-condensable gas [6-10], etc. The investigations in Reference [11] of average condensation heat transfer with the steam flow rate of $2.5-5.5 \mathrm{~g} / \mathrm{s}$ and non-condensable gas mass fraction from $0 \%$ to $10 \%$ in a vertical tube, whose active length of condensation was $\mathrm{x} / \mathrm{d} \approx 38$, demonstrated that condensation heat transfer decreases with the increase of the non-condensable gas fraction. The analysis of pressure influence also showed that, in the case of pressure decrease in the system, the obtained heat due to the condensation process also decreased. The calculated average condensation heat transfer coefficient at various experimental conditions (system pressure and inlet non-condensable gas mass fraction at inlet) varied from 3 to $10 \mathrm{~kW} / \mathrm{m}^{2} \cdot \mathrm{K}$.

The local condensation heat transfer of pure steam and a steam-nitrogen mixture in a vertical tube was investigated in Reference [12]. The investigations were performed in a relatively long vertical test section $(x / d \approx 230)$ with the measurements of the cooling water temperature, bulk steam temperature and tube wall temperature along the test section. The steam and the cooling water supply was performed in a counter-current configuration. The steam was supplied from the upper part of the test section. When the pure steam was supplied to the test section at a flow rate of about $11.2 \mathrm{~kg} / \mathrm{h}$, the bulk steam temperature was constant (about $100{ }^{\circ} \mathrm{C}$ ) almost till the middle of the condenser tube, i.e., up to $\mathrm{x} / \mathrm{d} \approx 107$, which indicated that condensation is taking place in that part of the test section. When $\mathrm{x} / \mathrm{d}$ was in the range from 107 to 162 , a sudden decrease in the bulk temperature to about $17^{\circ} \mathrm{C}$ was observed. From $\mathrm{x} / \mathrm{d} \approx 162$ until the end of the test section, the bulk temperature was almost constant. The bulk temperature breakdown at $\mathrm{x} / \mathrm{d} \approx 107$ means that, after that point, all the vapor was condensed and there was a single phase only, i.e., condensed water flowing in the tube. The character of the cooling water temperature was not so evidently expressed as that of the bulk steam temperature. The cooling water (flow rate $290 \mathrm{~kg} / \mathrm{h}$ ) temperature (at the inlet of about $17^{\circ} \mathrm{C}$ ) was changing insignificantly from the end of the test section until about $\mathrm{x} / \mathrm{d} \approx 107$. From $\mathrm{x} / \mathrm{d} \approx 107$ until the beginning of the test section, the cooling water temperature was increasing and reached almost $40{ }^{\circ} \mathrm{C}$. The obtained character of the water temperature clearly indicated when the water was gaining heat due to steam condensation. With the increase of non-condensable gas mass fraction up to $10.2 \%$, the bulk steam temperature drop was not so evidently expressed as in the case with pure steam. In this case, also, the decrease from about $100{ }^{\circ} \mathrm{C}$ at $\mathrm{x} / \mathrm{d} \approx 107$ was observed, and the temperature was continuously decreasing until the end of the test section, where it was about $60{ }^{\circ} \mathrm{C}$. Along all the test section, two-phase flow was observed, as not all the steam was condensed, as in the case before. The cooling water temperature was negligibly increasing from $\approx 17$ to $\approx 20{ }^{\circ} \mathrm{C}$ from the end of the test section until about $\mathrm{x} / \mathrm{d} \approx 107$. From $\mathrm{x} / \mathrm{d} \approx 107$ until the beginning of the test section, the increase was better expressed, meaning that the cooling water was heated from $\approx 20$ to $\approx 40{ }^{\circ} \mathrm{C}$. The analysis of the local condensation heat transfer showed that the increase of the non-condensable gas mass fraction significantly decreased the local condensation heat transfer. However, this was true until $\mathrm{x} / \mathrm{d} \approx 65$, and further from that point, the change of non-condensable gas mass fraction at the inlet from 3\% to $30 \%$ practically had no influence on heat transfer.

The results presented in papers [11,12] also generally reflect the main aspects occurring in vertical heat exchangers in the case of pure steam or steam condensation with small amount of non-condensable gas. The main conclusions determined in these works are that, in the case of pure steam, the condensation occurs almost in the initial part of the experimental section and it results in very high heat and mass transfer rates.

When incinerating biofuel or other fuels, the flue gas usually contains a relatively small amount ( $\sim-25 \%$ vol.) of water vapor and the remaining portion consisting of non-condensable gas is high. Thus, in the case of flue gas, the situation is different in comparison to that presented in References [11,12]. 
The condensation of flue gas generated by incinerating natural gas was studied in Reference [13]. The experiments were performed in a rather short vertical tube $\mathrm{x} / \mathrm{d} \approx 80$, with inlet water vapor volume fraction of $15-18 \%$. The Reynolds number for flue gas during the experiments was varied from 2300 to 5000 . The results indicated that the water vapor in the flue gas increased the average total heat transfer at least by about two times in comparison with dry air in the same range of Reynolds numbers. The ratio between sensible (by convection) and latent (by condensation) heat transfer increases with the cooling wall temperature decrease. The decrease of wall temperature of about 1.3 times, i.e., from about 49 to $38^{\circ} \mathrm{C}$, leads to the total heat transfer increase of almost up to 1.8 times. During the experiments, the average total Nusselt number for different cooling wall temperatures and Re numbers was in the range between 20 and 70. Wall temperature is also an important factor in terms of the condensing rate. It was determined that, in a certain wall temperature range $\left(49-38^{\circ} \mathrm{C}\right)$, the condensate mass flow rate increases by about three times, i.e., from $\approx 0.25$ to $\approx 0.7 \mathrm{~kg} /\left(\mathrm{m}^{2} \cdot \mathrm{s}\right)$.

Most of researchers do not use real flue gas but usually simulate them as an airvapor mixture. The air-vapor mixture was used for the analysis of heat and mass transfer in rather a short vertical tube of $x / d \approx 70$ in Reference [14]. The cooling agent in this study was air with the inlet temperature of $20^{\circ} \mathrm{C}$. The volumetric water vapor fraction during the experiment with condensation was about $17 \%$ and without condensationabout $1 \%$ without condensation. The flue gas temperature measured in the center of the test section for the case without condensation showed a decrease of about $12{ }^{\circ} \mathrm{C}$ from the inlet temperature, while for the case with condensation, the decrease observed was about $5{ }^{\circ} \mathrm{C}$ along the test section. Although during the experiments only $30 \%$ of water vapor was condensed, the average total heat transfer was almost two times higher in comparison with the experiments without condensation.

Results related to condensation of simulated flue gases in a vertical annulus, whose test section was about $x / d=32$, were presented in Reference [15]. At the inlet, the watervapor mass fraction was in the range from $5 \%$ to $12 \%$, and the Reynolds number was $\operatorname{Re}=4600-14,000$. When the vapor mass fraction was $5 \%$, the condensation rate was between 0.2 and $0.6 \mathrm{~kg} / \mathrm{h}$. When the vapor mass fraction was increased to $12 \%$, the condensation rate was from 1 to $2.8 \mathrm{~kg} / \mathrm{h}$ for the mentioned Reynolds number range. The measured wall temperature for all the experiments was gradually and almost linearly decreasing along the test section. The average condensation heat transfer coefficient for $\operatorname{Re}=4600$ and for water vapor fraction of $5 \%$ was determined to be almost the same as the sensible heat transfer coefficient. When the water vapor fraction was $12 \%$, the average condensation heat transfer coefficient for the same Re number was about five times higher in comparison with the sensible heat transfer coefficient. In general, the average condensation heat transfer was more effective when the inlet vapor mass fraction and the Re number were increased.

Other theoretical and experimental investigations also confirm that condensation of water vapor from flue gas has a noticeable impact on heat transfer [16,17], etc.

Therefore, the literature review shows that there is a very broad topic to study: local heat-transfer processes in flue gas condensers, using real flue gas from boilers in the real range of their operational parameters, with a relatively small amount of water vapor ( 5-25\% vol.).

The current investigations of water vapor condensation from biofuel flue gas in a model of the vertical condensing heat exchanger (a long tube with $x / d \approx 170$ ) were performed with and without injection of water into the calorimetric tube. This paper presents the base case experimental results without injection of water at the inlet to the calorimetric tube, analyzing temperature and local total heat transfer variations along the mentioned model (vertical tube) of the condensing heat exchanger.

\section{Experimental Setup}

The experimental setup used for the investigations of water vapor condensation from flue gas is presented in Figure 1. Flue gas was generated by incinerating wood pellets 
in a class 3 (according to EN303-5:2012) automatic boiler Kostrzewa (Poland, Gizycko). The boiler's power (maximum $50 \mathrm{~kW}$ ) can be adjusted in the range from $50 \%$ to $100 \%$. Generated flue gas with the temperature of about $180-190^{\circ} \mathrm{C}$ (at the exit from the boiler) was directed to the experimental section. For flue gas temperature regulation, the boiler's power and the economizer of the boiler were used.

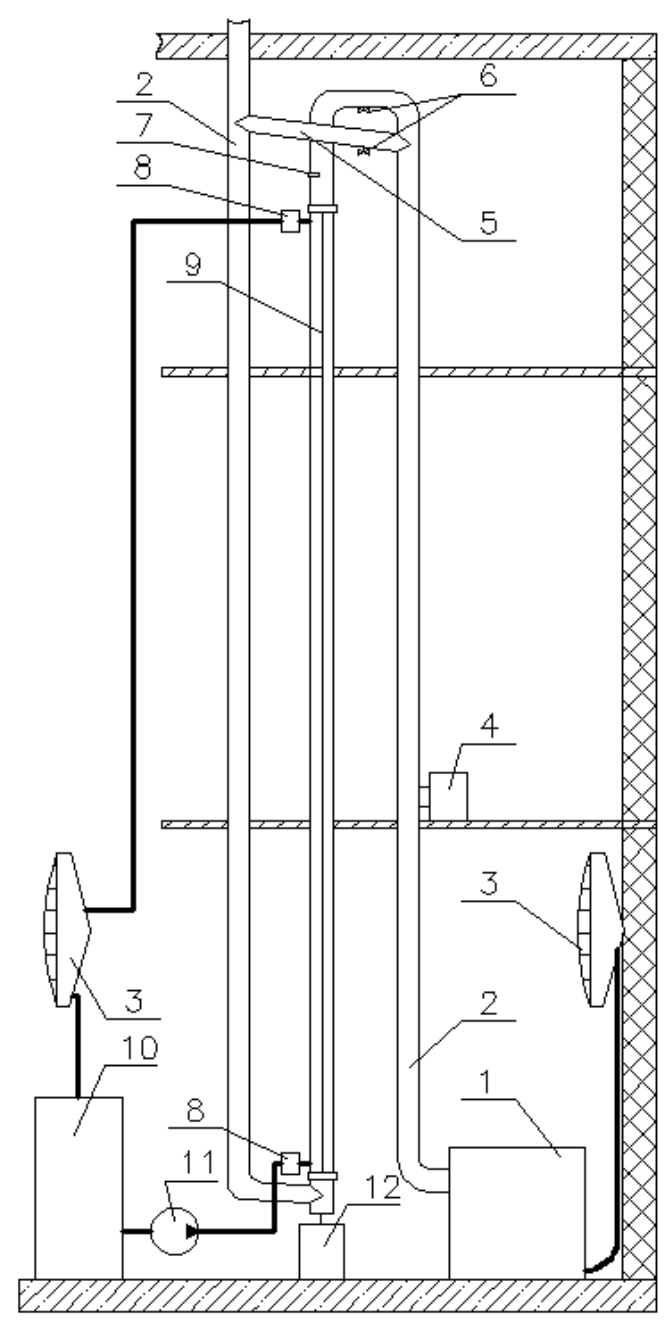

Figure 1. Experimental setup (not to scale): (1) boiler; (2) flue gas pipe; (3) heat exchanger (fan coil); (4) flue gas exhauster; (5) by-pass pipe; (6) damper; (7) inlet flue gas flow rate, temperature, and humidity measurement point; (8) water mixer; (9) vertical calorimetric tube as model of flue gas condensing heat exchanger (economizer); (10) water tank; (11) water pump; and (12) condensate collection tank.

The flue gas flow rate was adjusted by the valves. Then the flue gas flew inside the vertical calorimetric tube and was directed to the flue gas pipe (chimney) and discharged into the environment.

The test section was made of stainless steel. It was composed of an internal calorimetric tube (length $\mathrm{x} \approx 5.8 \mathrm{~m}$, inner diameter $\mathrm{d}=0.034 \mathrm{~m}$, wall thickness $\delta=2 \mathrm{~mm}, \mathrm{x} / \mathrm{d} \approx 170$ ), where condensation on the internal surface takes place, and of an outer tube (length $\mathrm{x} \approx 5.9 \mathrm{~m}$, inner diameter $\mathrm{D}=0.108 \mathrm{~m}$ ) with cooling water. The experimental section as well as the flue gas pipe (chimney) was insulated by using $5 \mathrm{~cm}$ thickness Rockwool insulation.

For cooling of the calorimetric tube, distilled water was supplied to the space between the inner and the outer tubes from the storage tank, using a water pump. The weighting method was used to measure the water flow rate, which was then adjusted by regulating a corresponding valve. Before entering the experimental section, water was mixed in a water mixer to have a uniform temperature. When leaving the experimental section, the water 
was also mixed in the same type of a water mixer. After the mixer, the water passed the heat exchanger (air-water) to cool down and then was directed back to the water tank.

The water condensed on the calorimetric tube inner wall was drained into the condensate collection tank.

\section{Methodology}

The investigations were performed at different temperatures of flue gas and at two humidity levels of flue gas at the inlet to the calorimetric tube. The mass fraction of water vapor was about $7 \%$ in flue gas when biofuel pellets were incinerated in the boiler. When hot water was additionally sprayed into the furnace of the boiler with the purpose to simulate the incineration of more humid biofuel, the water-vapor mass fraction increased till about $17 \%$.

Temperature measurements were carried out by using calibrated chromel-copel thermocouples (wire diameter $0.2 \mathrm{~mm}$, accuracy $\pm 0.3 \%$ ) directly connected to the dataacquisition system:

- Twenty thermocouples were installed in the center of the calorimetric tube $\left(t_{c}\right)$ to measure the flue gas temperature along the tube. The distance between the thermocouples was approximately $0.28 \mathrm{~m}$.

- Twenty thermocouples were installed at the inner wall of the calorimetric tube $\left(t_{w}\right)$ along the length of the tube. The distance between the thermocouples was approximately $0.28 \mathrm{~m}$.

- Ten thermocouples were installed between the inner and the outer tubes to measure the cooling water temperature $\left(t_{\mathrm{cw}}\right)$ along the space between the tubes. The distance between the thermocouples was approximately $0.56 \mathrm{~m}$.

- Three thermocouples were installed in each of the water mixers to measure cooling water temperatures at the inlet and the outlet of the test section.

More detailed information is provided in the Table 1.

Table 1. Distribution of temperature measurement points.

\begin{tabular}{cc}
\hline Temperature & $\mathrm{x} / \mathrm{d}$ \\
\hline \multirow{2}{*}{$\mathrm{t}_{\mathrm{c}}$} & $7.2 ; 15.4 ; 23.7 ; 31.9 ; 40.1 ; 48.4 ; 56.6 ; 64.9 ; 73.1 ; 81.3 ; 89.6 ; 97.8 ; 106.0 ; 114.3 ;$ \\
& $122.5 ; 130.7 ; 139.0 ; 147.2 ; 155.4 ; 163.7$. \\
\hline \multirow{2}{*}{$\mathrm{t}_{\mathrm{w}}$} & $7.2 ; 23.7 ; 40.1 ; 56.6 ; 73.1 ; 89.6 ; 106.0 ; 122.5 ; 139.0 ; 155.4$. \\
\hline \multirow{2}{*}{$\mathrm{t}_{\mathrm{cW}}$} & $7.2 ; 15.4 ; 23.7 ; 31.9 ; 40.1 ; 48.4 ; 56.6 ; 64.9 ; 73.1 ; 81.3 ; 89.6 ; 97.8 ; 106.0 ; 114.3 ;$ \\
& $122.5 ; 130.7 ; 139.0 ; 147.2 ; 155.4 ; 163.7$. \\
\hline
\end{tabular}

During the experiments, all thermocouple readings were collected by using the Keithley automatic data acquisition system (accuracy $\pm 0.25 \%$ ).

The parameters of the boiler (flue gas temperature, supply and return water temperature, chimney draft) were automatically registered every $5 \mathrm{~min}$, using the KD7 data recording system. The flue gas temperature $\left(\mathrm{t}_{\mathrm{in}},{ }^{\circ} \mathrm{C}\right)$ and the relative humidity $\left(\mathrm{RH}_{\mathrm{in}}, \%\right)$ at the inlet to the experimental section were measured with a KIMO C310 (Switzerland) temperature and humidity sensor. The accuracy for $\mathrm{RH}_{\mathrm{in}}$ measurement is $\pm 0.88 \%$ and for temperature $\pm 0.3 \%$. The sensor was installed about $25 \mathrm{~cm}$ above the calorimetric tube. The inlet flue gas velocity (for determination of the flow rate) was measured by using a bellmouth with installed Pitot-Prandtl tubes, which were connected to the micromanometer (accuracy $\pm 1.5 \%$ ). The flow rate of cooling water during the experiments was approximately $\approx 33 \mathrm{~kg} / \mathrm{h}$.

Before the experiments, the humidity of the biofuel pellets was measured by using a biofuel moisture meter BIO-1 (Poland), which has the accuracy of $\pm 1.5 \%$. The measured humidity was low (when it is lower than $8 \%$, the biofuel moisture meter indicates the humidity value as "low"). 
In the formulas presented further, all the properties $\left(c_{p}, \lambda\right.$, etc. $)$ of the gas, i.e., the mixture of flue gas and water vapor, were calculated by using formulas for mixture properties calculation [18]. The calculation of the properties is based on flow temperature measured in the center of the calorimetric tube.

The local (represented by index, $i$, in formulas further) total (convection and condensation) heat transfer coefficient and the Nusselt number were calculated in 20 positions along the tube where flow temperature in the center of the tube and inner wall temperatures were measured.

Total local heat flux was obtained as follows:

$$
q_{t_{i}}=\frac{m_{H 2 O_{i}} \cdot c_{p H 2 O_{i}}}{\pi \cdot d} \cdot \frac{d t_{H 2 O_{i}}}{d x},
$$

where $m_{\mathrm{H} 2 \mathrm{O}}$ is inlet mass flow rate of the cooling water, $\mathrm{kg} / \mathrm{s} ; c_{p H 2 \mathrm{O}}$ is specific heat of the water, $\mathrm{kJ} / \mathrm{kg} \cdot{ }^{\circ} \mathrm{C}$; $\mathrm{d}$ is the inner diameter of the calorimetric tube, $\mathrm{m} ; d t_{H 2 O} / d_{x}$ is the slope of the cooling water temperature gradient, which was determined as the least squares polynomial fit of the coolant temperature as a function of the length of the heat exchanger model.

The local total heat transfer coefficient was calculated as follows:

$$
\alpha_{t_{i}}=q_{t_{i}} /\left(t_{c}-t_{w}\right)_{i}
$$

where $t_{c}$ is the temperature measured in the center of the calorimetric tube, ${ }^{\circ} \mathrm{C} ; t_{w}$ is the measured inner wall temperature of the calorimetric tube, ${ }^{\circ} \mathrm{C}$.

The total Nusselt number:

$$
N u_{t_{i}}=\alpha_{t_{i}} \cdot d / \lambda_{i}
$$

To evaluate the performance of the heat exchanger, the condensation efficiency (\%) parameter was used [19]. This parameter was calculated as follows:

$$
n_{c d}=\frac{m_{c d}}{m_{H 2 O_{i n}}} \cdot 100
$$

where $m_{c d}$ is the condensate mass flow rate, $\mathrm{kg} / \mathrm{s} ; m_{\mathrm{H} 2 \mathrm{Oin}}$ is the water vapor (in flue gas) inlet flow rate, $\mathrm{kg} / \mathrm{s}$. The condensate flow rate was calculated based on the condensate level increase in the condensate collection tank and time during which the condensate was collected.

The accuracy of the data was evaluated by using the methodology presented in Reference [20]. The highest uncertainties are at the end of the tube, where the temperature difference between flue gas and tube wall is the smallest. For the Nusselt number, this uncertainty is $6-14 \%$.

\section{Results Analysis}

As it has been indicated earlier, the experiments were carried out at different temperatures and for two humidity levels of flue gas at the inlet to the calorimetric tube. During the incineration of biofuel pallets in the boiler, the mass fraction of water vapor in flue gas was about $7 \%$. When hot water (about $70^{\circ} \mathrm{C}$ ) was additionally sprayed into the furnace of the boiler, the water-vapor mass fraction increased until about $17 \%$.

\subsection{Water-Vapor Mass Fraction $7 \%$}

Figure 2 presents some typical distributions of temperatures along the tube (the model of the condensing heat exchanger) at different Reynolds inlet numbers $\left(\operatorname{Re}_{\text {in }}\right)$, different inlet flue gas temperatures and an almost constant condensable gas (water vapor) mass fraction $\mathrm{m}_{\mathrm{cd}} \approx 7 \%$ when no water was sprayed into the furnace of the boiler. The dew point temperature at the inlet to the test section for the presented cases was in the range of $46-49^{\circ} \mathrm{C}$ and was calculated based on measured $\mathrm{RH}_{\text {in }}$ and $\mathrm{t}_{\text {in }}$ and using equations presented in Reference [21]. The inlet cooling water temperature was in the range of $25-27^{\circ} \mathrm{C}$. 
It is known that, when the condenser wall temperature from the flue gas flow side is lower than the dew point temperature, water vapor starts to condensate on the wall of the calorimetric tube. If the temperature of the flue gas in the center of the calorimetric tube reaches the dew point temperature, water vapor should start to condense in all its volume.

For the case presented in Figure 2a, the wall temperature (curve 2) is below the dew point temperature. Hence, from the inlet to the tube the condensation on the wall is going on. In other cases (Figure $2 b-d$ ), the wall temperature near the flue gas inlet is very close to the dew point temperature or even slightly exceeds it. Therefore, condensation cannot start on the wall from the very beginning of the tube, or it is very week. The decrease of the flow temperature in the center of the tube indicates the cooling of the flow. Due to this, almost a linear decrease in the temperature of the flue gas is observed initially (Figure 2, curve 1) until the temperature reaches the dew point temperature. Therefore, flow cooling by convection is prevailing in this part.

Figure 2 shows that, with an increase in $\operatorname{Re}_{\text {in }}$, the part of the calorimetric tube where convection is prevailing extends. When $\operatorname{Re}_{\text {in }} \approx 11,800$ convection is prevailing region is observed from the beginning of the calorimetric tube until $x / d \approx 30-40$ (Figure $2 a, b$ ). For the cases when $\operatorname{Re}_{\mathrm{in}}$ was increased to 23,000 (Figure $2 \mathrm{~b}, \mathrm{c}$ ), it has extended further, i.e., until $\mathrm{x} / \mathrm{d} \approx 60-70$.

After a linear decrease in the flue gas temperature, some regions with temperature fluctuations occurs. At lower $\mathrm{Re}_{\mathrm{in}}$ and at higher $\mathrm{Re}_{\mathrm{in}}$ (Figure $2 \mathrm{~b}, \mathrm{c}$ ), these temperature fluctuations are not clearly expressed. Clearly expressed flue gas temperature fluctuations were observed at $\operatorname{Re}_{\text {in }}$ when the flue gas inlet temperature was about $95^{\circ} \mathrm{C}$ (Figure $2 \mathrm{~d}$ ), just before the flue gas temperature in the center of the calorimetric tube reached the dew point temperature. It is possible that these fluctuations show fog formation in the total cross-section of the calorimetric tube. As the fog forms in the total cross-section of the tube, it is likely that the formed water droplets splash thermocouple and due to this, a local temperature fluctuation with some minimum of flue gas temperature was determined; however, more investigations are needed to understand this process.

When the flue gas temperature in the whole cross-section reaches the dew point temperature, the character of flue gas temperature in the center of the tube changes and the temperature decrease is much slower. This indicates that the condensation process dominates, but it is not as intensive as in the case of pure water vapor condensation when the temperature of the flow along the tube does not change as it was presented in References [12,18].

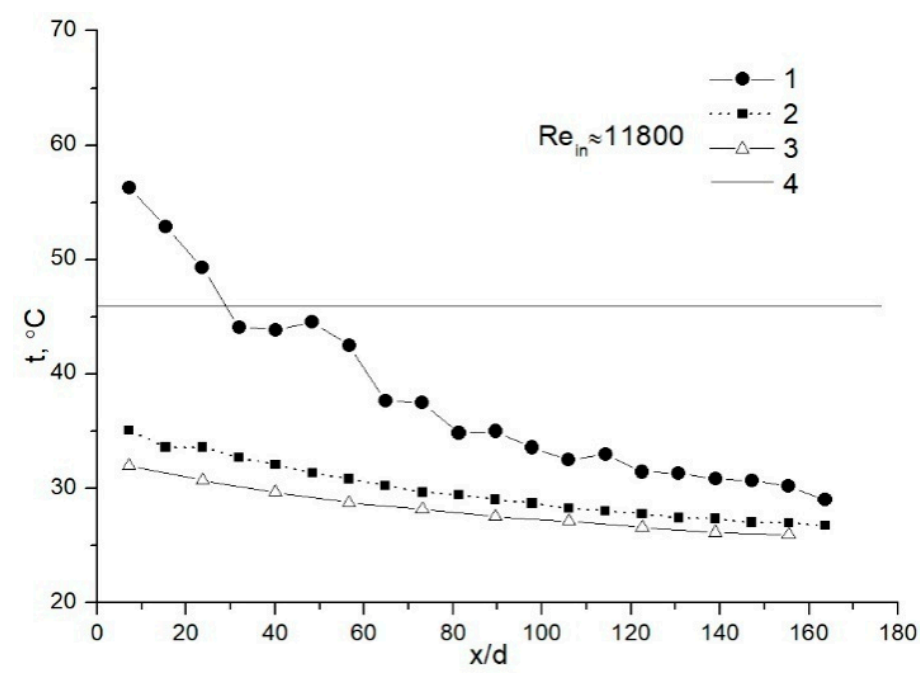

(a)

Figure 2. Cont. 


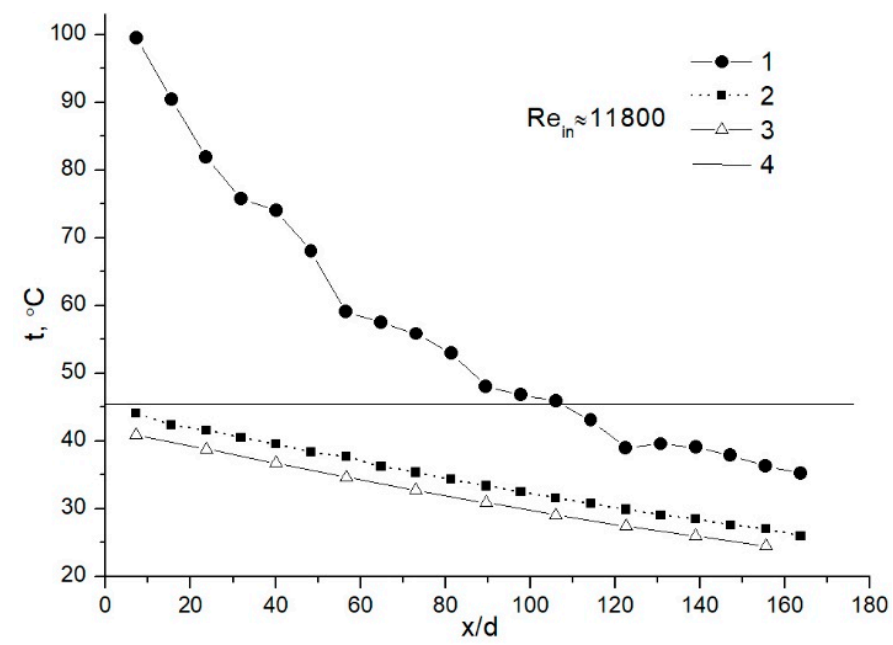

(b)

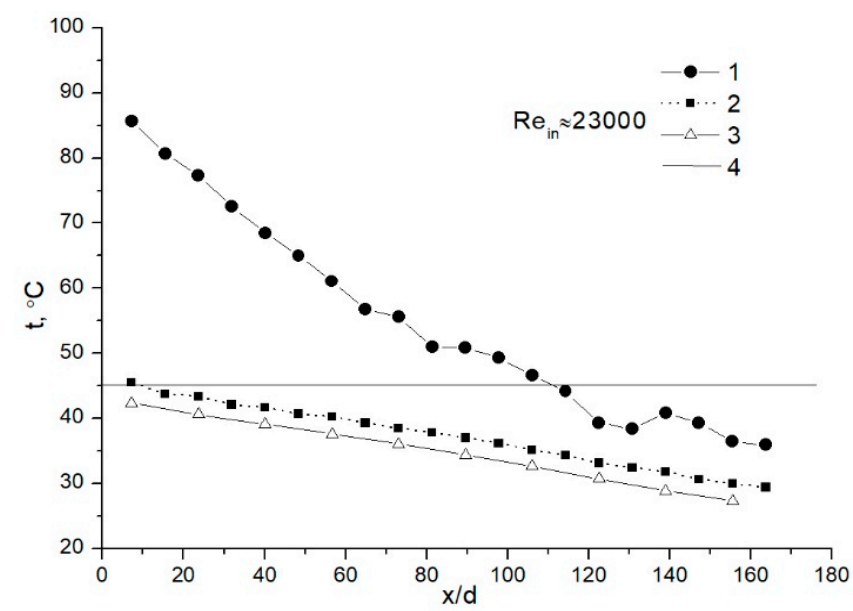

(c)

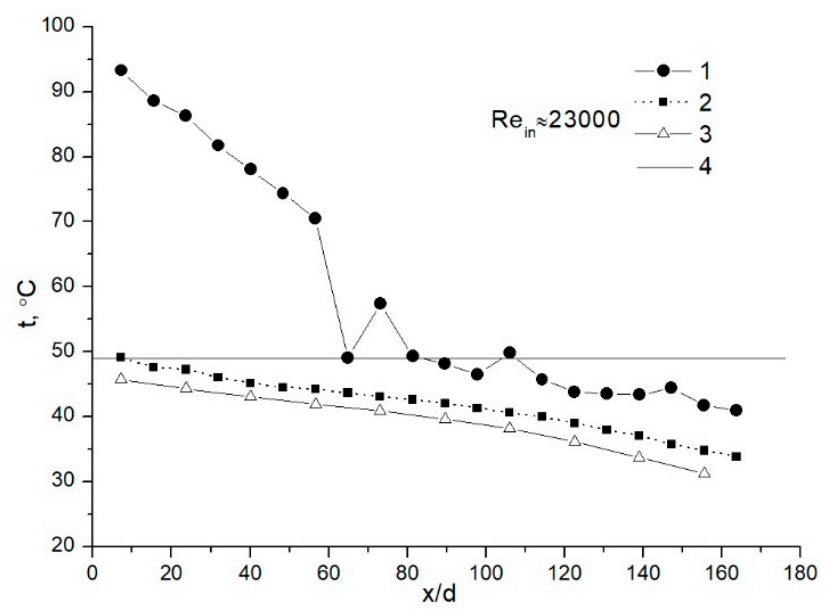

(d)

Figure 2. Temperature variation along the model of the condensing heat exchanger at a constant inlet water-vapor mass fraction of approximately $7 \%$ and at different flue gas inlet temperatures (a) $\mathrm{Re}_{\text {in }} \approx 11,800, \mathrm{t}_{\text {in }} \approx 58{ }^{\circ} \mathrm{C},(\mathrm{b}), \mathrm{Re}_{\mathrm{in}} \approx 11,800, \mathrm{t}_{\mathrm{in}} \approx 100{ }^{\circ} \mathrm{C},(\mathrm{c}) \mathrm{Re}_{\mathrm{in}} \approx 23,000, \mathrm{t}_{\mathrm{in}} \approx 85{ }^{\circ} \mathrm{C}$ (d) $\operatorname{Re}_{\text {in }} \approx 23,000, \mathrm{t}_{\text {in }} \approx 95^{\circ} \mathrm{C}$ (1) center of the calorimetric tube, (2) inner wall of the calorimetric tube, (3) cooling water in the middle between inner and outer tubes, and (4) dew point temperature at the inlet to the calorimetric tube. 
The higher was the inlet flue gas temperature, the higher the calorimetric tube wall temperature was observed. The variation of the calorimetric tube wall temperature for all the analyzed cases is practically similar to the variation of the cooling water temperature. The cooling water temperature increases faster at the beginning of the water inlet $(x / d \approx 170-140)$ where condensation of water vapor prevails. This is more clearly expressed in the case of a higher inlet flue gas temperature and a higher Reynolds number $\left(\operatorname{Re}_{\mathrm{in}} \approx 23,000\right)$ (Figure $2 \mathrm{~d}$, curve 4$)$.

Variation in the total Nusselt number with the $\mathrm{Re}_{\text {in }}$ number at different inlet flue gas temperatures is shown in Figure 3. For a lower $\operatorname{Re}_{\text {in }}$ number (Figure $3 a, \operatorname{Re}_{\text {in }} \approx 11,800$ ), the total Nusselt number is rather high even at the beginning of the calorimetric tube. This is related to the fact that the calorimetric tube wall temperature is low in comparison with the dew point temperature (Figure 2a), and due to this temperature difference, the favorable conditions for condensation are created. Further on, in the case of a lower flue gas inlet temperature (Figure $2 \mathrm{a}$ ), heat transfer reaches the maximum value of $\mathrm{Nu}_{\mathrm{t}} \approx 95$ at about $\mathrm{x} / \mathrm{d} \approx 100$ and then starts to decrease (Figure $3 \mathrm{a}$ ). At the end of the calorimetric tube, the Nusselt number is even slightly lower than it was at the beginning. This could be related to the fact that the condensation influence on heat transfer became less strong as some amount of water vapor had already been condensed and temperature differences were rather small.

When the flue gas inlet temperature is increased (Figure 3a), the total heat transfer increases more rapidly in comparison with the case before. The increase is observed even until $\mathrm{x} / \mathrm{d} \approx 120$ and after that, some stabilization of heat transfer occurs. This could be related to an almost constant difference between the flue gas temperature and the tube wall temperature. In any case, the maximum value of $\mathrm{Nu}_{\mathrm{t}} \approx 200$ is almost twice higher than it was determined at a lower flue gas inlet temperature.

At higher $\operatorname{Re}_{\text {in }}$ numbers (Figure $3 b$ ), the heat transfer at the beginning of the calorimetric tube is slightly lower in comparison with the lower $\operatorname{Re}_{\text {in }}$ number discussed earlier. In case of higher $\operatorname{Re}_{\text {in }}$ numbers, the tube wall temperature is very close to the dew point temperature or slightly higher at the beginning of the calorimetric tube (Figure 2c,d), and therefore condensation cannot occur from the very beginning of the calorimetric tube or it is very week.

At $\operatorname{Re}_{\text {in }} \approx 23,000$ for both inlet flue gas temperatures (Figure 2c,d), the heat transfer increases rather intensively with the distance of the tube (Figure 3b). For the lower inlet flue gas temperature, the heat transfer constantly increases until the end of the tube. For the higher inlet flue gas temperature, three zones of the $\mathrm{Nu}_{\mathrm{t}}$ variation can be distinguished: the first one is from the beginning of the tube, where the heat transfer gradually increases until about $x / d \approx 50$, the second one is from $x / d>50$, when a rather sharp increase of heat transfer is observed, and the third one from $x / d$ of about 110 when $\mathrm{Nu}_{\mathrm{t}}$ starts to stabilize. Such intensification of heat transfer could be related with prevailing of the condensation due to a decrease in the flow temperature in whole cross-section below the dew point temperature.

\subsection{Water-Vapor Mass Fraction 17\%}

In order to increase moisture content in the flue gas and to reveal differences in temperature variations and heat transfer in comparison with the previous case, hot water was sprayed into the furnace of the boiler, but the $\operatorname{Re}_{\text {in }}$ numbers were kept almost the same.

The dew point temperature at the inlet to the test section for the presented cases was in the range of $58-67^{\circ} \mathrm{C}$, and it was calculated based on the measurements of the $\mathrm{RH}_{\text {in }}$ and $t_{\text {in }}$ and using equations presented in Reference [21]. The inlet cooling water temperature was in the range of $26-29^{\circ} \mathrm{C}$.

It can be seen (Figure 4a) that the tube wall temperature is close but still below the dew point temperature at the inlet to the tube. 


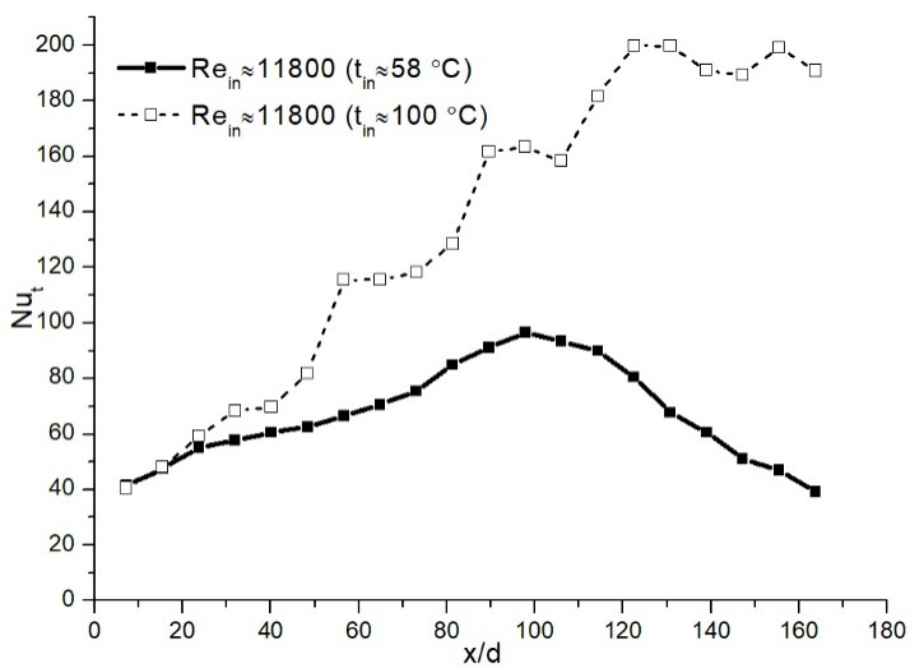

(a)

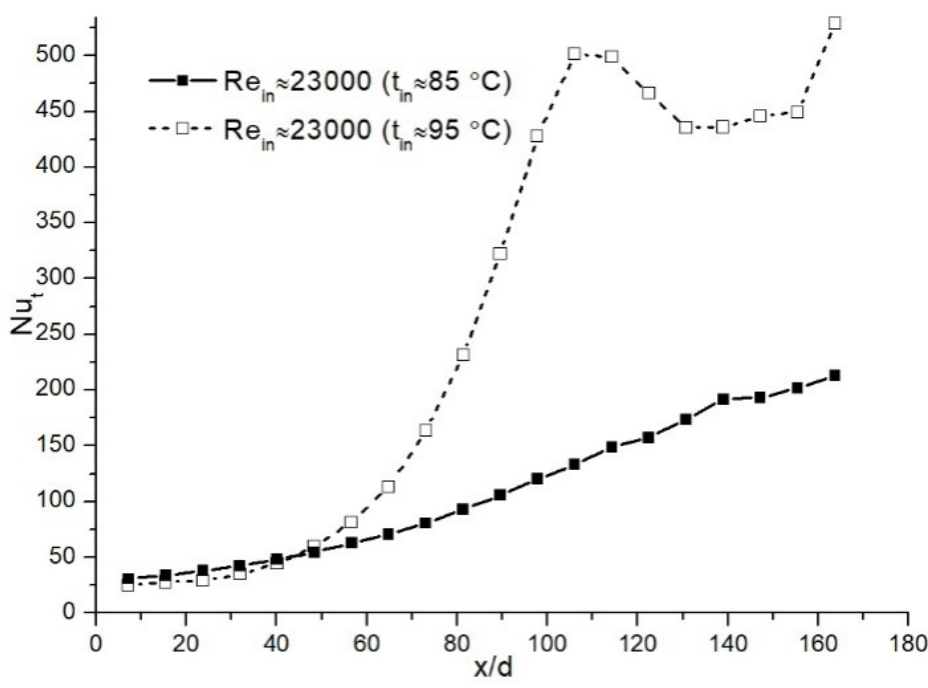

(b)

Figure 3. Variation of the total Nusselt number along the model of the condensing heat exchanger at a constant inlet water-vapor mass fraction of approximately $7 \%$, different flue gas inlet temperatures and Reynolds numbers: (a) $\operatorname{Re}_{\text {in }} \approx 11,800, \mathrm{t}_{\text {in }} \approx 58{ }^{\circ} \mathrm{C}$ and $\mathrm{t}_{\mathrm{in}} \approx 100{ }^{\circ} \mathrm{C},(\mathbf{b}) \operatorname{Re}_{\mathrm{in}} \approx 23,000, \mathrm{t}_{\mathrm{in}} \approx 85^{\circ} \mathrm{C}$ and $\mathrm{t}_{\text {in }} \approx 95^{\circ} \mathrm{C}$

This means that condensation on the wall takes place from the very beginning of the tube. In other cases (Figure $4 b-d$ ) at $x / d$ until 50-80, the tube wall temperature exceeds the dew point temperature. Therefore, no condensation occurs in these regions and the flow is cooled due to convection. It must be stressed that, for a higher $\operatorname{Re}_{\mathrm{in}}$ number and a higher inlet temperature (Figure $4 \mathrm{~d}$ ), this region extended to a higher $\mathrm{x} / \mathrm{d}$ value, until about $\mathrm{x} / \mathrm{d} \approx 80$.

The variations in the tube wall temperature and in the cooling water temperature (Figure 4) are rather similar. However, comparing the current cases with the results presented in Figure 2, it can be seen that the cooling water temperature increases much faster from the water inlet $(\mathrm{x} / \mathrm{d} \approx 170)$ until a certain point in the test section. The increase in the cooling water temperature is very well expressed till the points where the condensation begins, and this results in a water temperature increase by about $22-24^{\circ} \mathrm{C}$ when $\operatorname{Re}_{\text {in }} \approx 11,800$ (Figure $4 a, b$ ) or even more, i.e., by about $22-27^{\circ} \mathrm{C}$ when $\operatorname{Re}_{\text {in }} \approx 20,200$ (Figure $4 c, d)$. Further, until the cooling water exits the test section (at $x / d=0)$, the increase in its temperature is much modest, i.e., by about $7-8{ }^{\circ} \mathrm{C}$. 


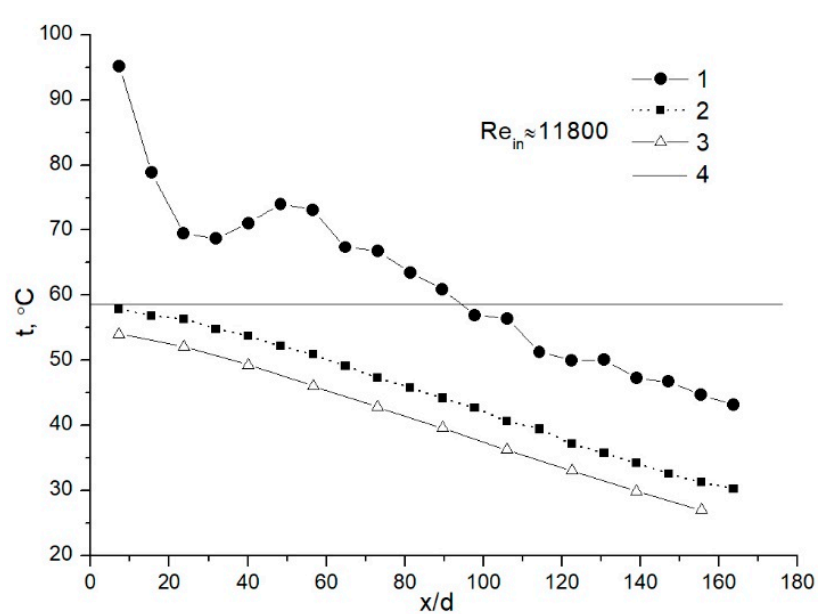

(a)

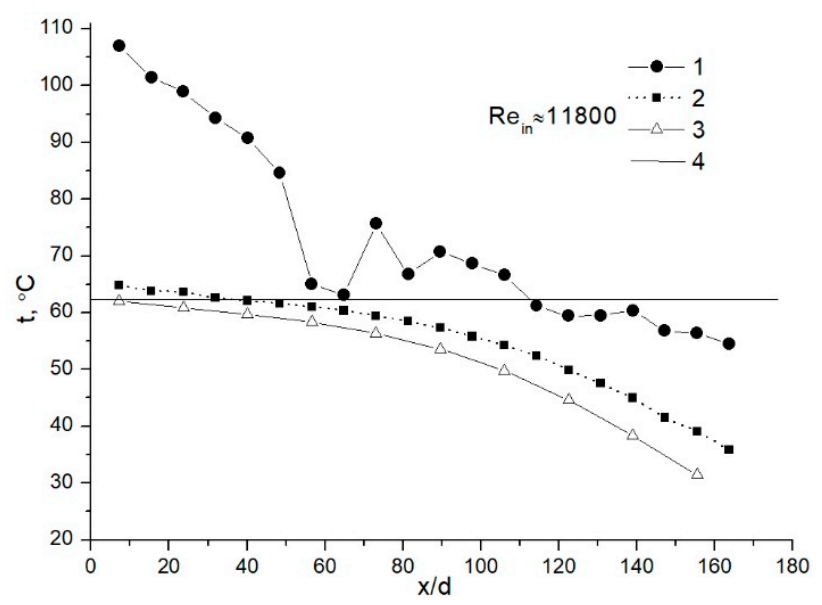

(b)

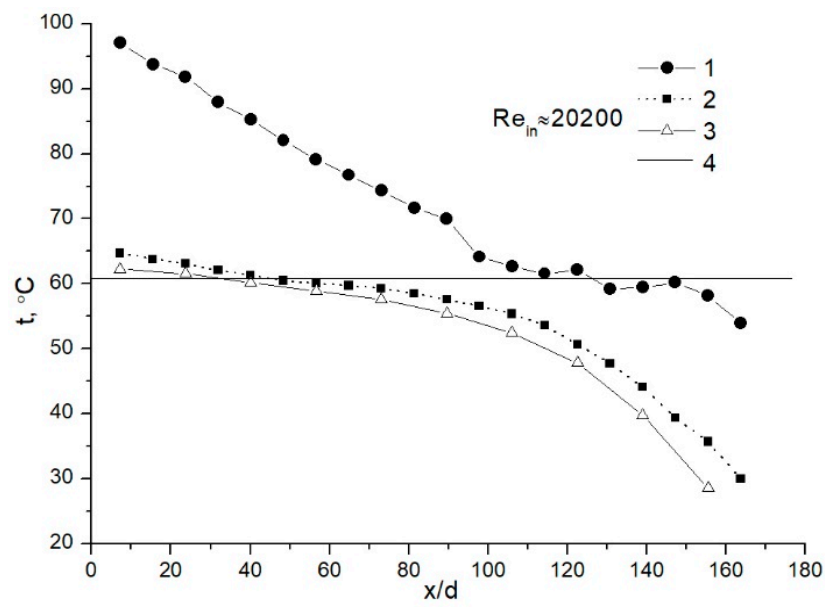

(c)

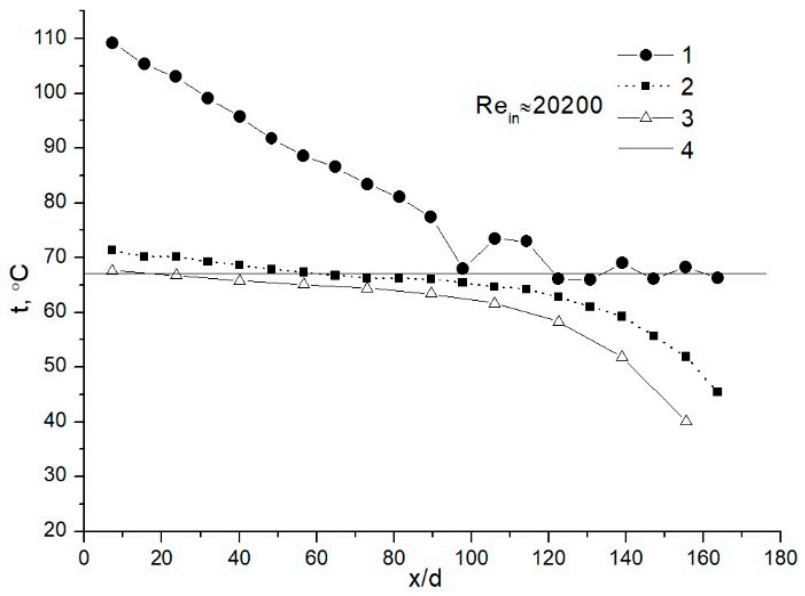

(d)

Figure 4. Temperature variation along the model of the condensing heat exchanger at a constant inlet water-vapor mass fraction of approximately $17 \%$ and different flue gas inlet temperatures $(\mathbf{a}) \operatorname{Re}_{\text {in }} \approx 11,800, \mathrm{t}_{\mathrm{in}} \approx 95{ }^{\circ} \mathrm{C},(\mathbf{b}) \operatorname{Re}_{\text {in }} \approx 11,800$, $\mathrm{t}_{\mathrm{in}} \approx 107^{\circ} \mathrm{C}$, (c) $\operatorname{Re}_{\mathrm{in}} \approx 20,200, \mathrm{t}_{\mathrm{in}} \approx 97^{\circ} \mathrm{C}(\mathrm{d}) \mathrm{Re}_{\mathrm{in}} \approx 20,200, \mathrm{t}_{\mathrm{in}} \approx 110^{\circ} \mathrm{C}$. (1) center of calorimetric tube, (2) inner wall of the calorimetric tube, (3) cooling water in the gap between the inner and the outer tubes, and (4) dew point temperature at the inlet to the calorimetric tube.

The regions of prevailing convection and condensation are very clearly demonstrated by the total Nusselt number variation along the tube (Figure 5). At the beginning of the calorimetric tube, the $\mathrm{Nu}_{t}$ for a lower $\mathrm{Re}_{\text {in }}$ number and a lower inlet flue gas temperature (Figure 5a) is slightly higher in comparison to that at a higher inlet flue gas temperature. The condensation heat transfer in the first case and the convection heat transfer in the second one could explain such a difference, as it was indicated above. For the first case, with the further distance the heat transfer increase is noticed until it reaches the maximum value of about $\mathrm{Nu}_{\mathrm{t}}=200$, and then, as in the case for a lower condensable gas mass fraction (Figure 3a), the heat transfer starts to decrease, likely for the reasons already discussed in previous sections. For the case with a higher inlet flue gas temperature, the heat transfer gradually increases from the beginning of the tube until about $x / d \approx 50$. Then a sharp increase follows due to a condensation occurrence in almost all the volume of the calorimetric tube (Figure $4 \mathrm{~b}$, see curve 1 ). Later it starts to stabilize and stays in the range of $\mathrm{Nu}_{\mathrm{t}} \approx 375-425$ in the remaining part of the calorimetric tube. 


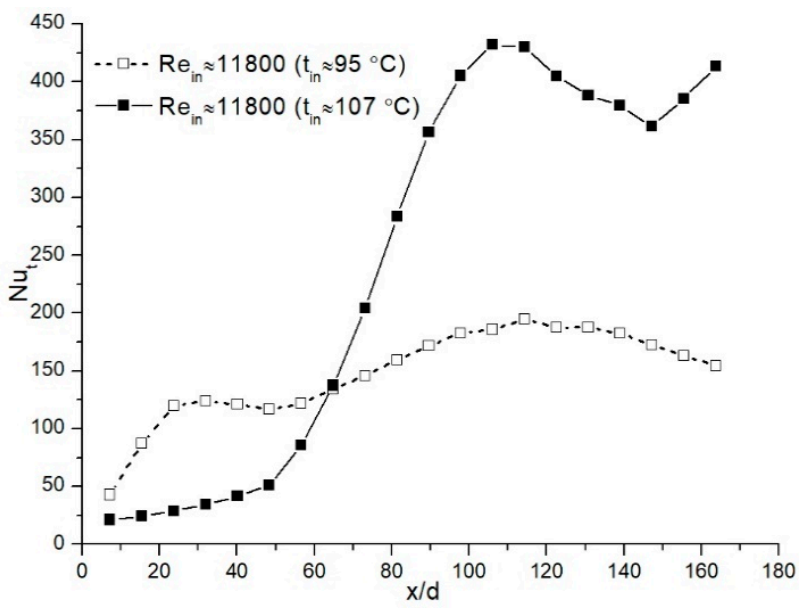

(a)

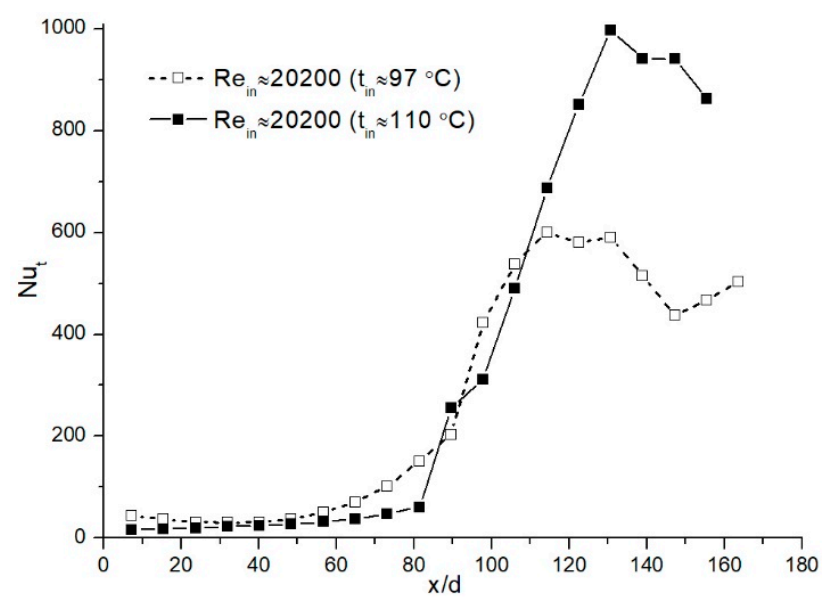

(b)

Figure 5. Distribution of the total Nusselt number along the model of the condensing heat exchanger at a constant inlet water-vapor gas mass fraction of approximately $17 \%$ and different flue gas inlet temperatures and Reynolds numbers: $(\mathbf{a}) \operatorname{Re}_{\text {in }} \approx 11,800, \mathrm{t}_{\mathrm{in}} \approx 95^{\circ} \mathrm{C}$ and $\mathrm{t}_{\text {in }} \approx 107^{\circ} \mathrm{C},(\mathbf{b}) \operatorname{Re}_{\text {in }} \approx 20,200$, $\mathrm{t}_{\text {in }} \approx 97^{\circ} \mathrm{C}$ and $\mathrm{t}_{\text {in }} \approx 110^{\circ} \mathrm{C}$.

When $\operatorname{Re}_{\text {in }}$ is higher (Figure $5 b$ ) and the flue gas temperature is lower, the convection heat transfer extends until $\mathrm{x} / \mathrm{d} \approx 60$. After that, the heat transfer increases rather steeply due to the condensation of water vapor and at $\mathrm{x} / \mathrm{d} \approx 110$ reaches the maximum value of $\mathrm{Nu}_{\mathrm{t}} \approx 600$. After that, some variation could be observed. At a higher inlet flue gas temperature, the convection heat transfer is almost constant until $\mathrm{x} / \mathrm{d} \approx 80$. After that, a sharp increase is noticed in the heat transfer due to water vapor condensation, which reaches the maximum value of $\mathrm{Nu}_{\mathrm{t}} \approx 1000$ at $\mathrm{x} / \mathrm{d} \approx 130$, and further, as in the case before, some variation is observed.

In general, the results presented in Figure 5 show that, in the case of high $\operatorname{Re}_{\text {in }}$ numbers, almost half of the calorimetric tube of the heat exchanger (the model of the economizer), where heat from flue gas is recovered by convection, would be used inefficiently in terms of the heat transfer process.

\subsection{Comparison of the Results for Different Water-Vapor Mass Fractions}

The influence of the water-vapor mass fraction on the total local heat transfer at a constant $\mathrm{Re}_{\mathrm{in}}$ number and a high inlet flue gas temperature was also analyzed. The results in Figure 6 show that the increase in the water-vapor mass fraction from $\approx 7 \%$ to $\approx 17 \%$ has a significant impact on heat transfer. 


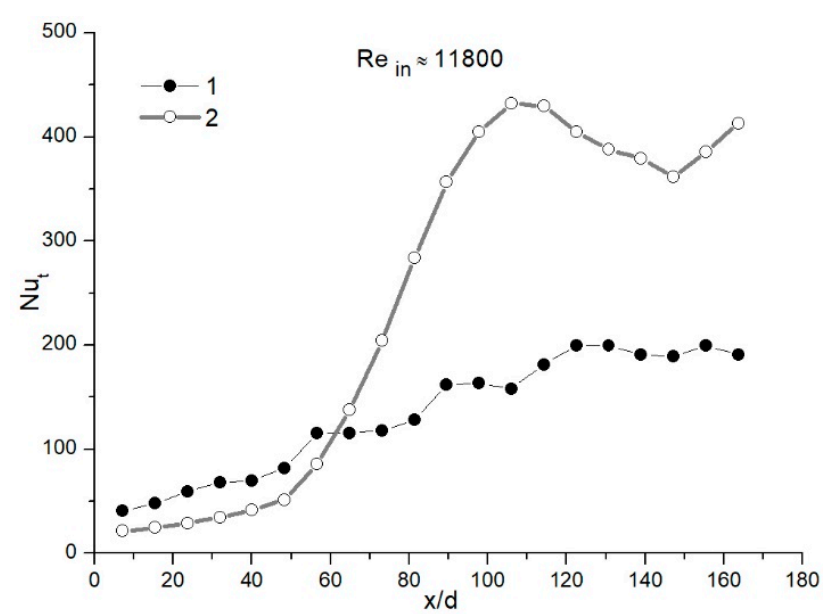

(a)

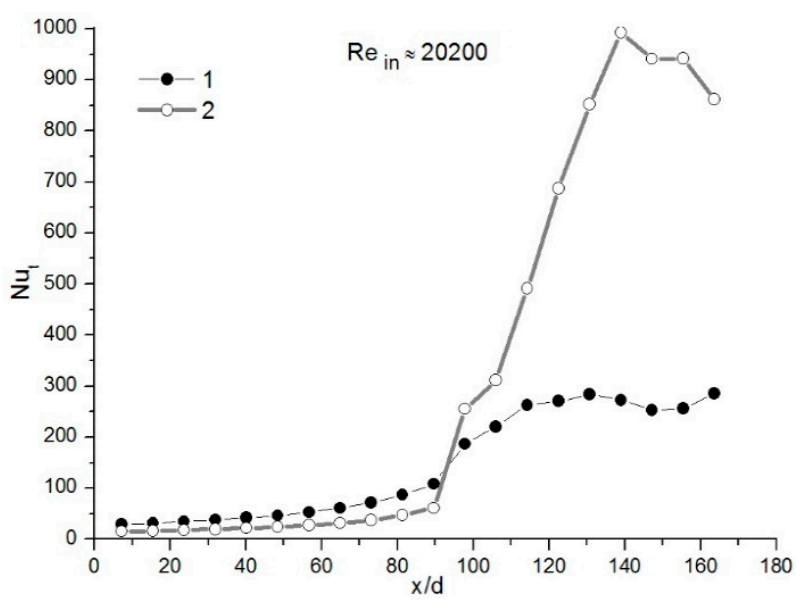

(b)

Figure 6. Variation of the total Nusselt number along the model of the condensing heat exchanger at a different water-vapor mass fraction but a constant $\operatorname{Re}_{\text {in }}(a) \operatorname{Re}_{\text {in }} \approx 11,800$, (b) $\operatorname{Re}_{\text {in }} \approx 20,200$ : (1) $\mathrm{m}_{\mathrm{cd} \text { in }} \approx 7 \%$ and $(2) \mathrm{m}_{\mathrm{cd}}$ in $\approx 17 \%$.

For the case with the smaller $\mathrm{Re}_{\mathrm{in}}$ number (Figure $6 \mathrm{a}$ ), the increase in the water-vapor mass fraction resulted in an increase in the total heat-transfer peak value by about 2.2 times till about 450 and for the higher $\operatorname{Re}_{\text {in }}$ number (Figure $6 \mathrm{~b}$ ) by about 3.4 times, till about 1000. The results presented in Figure 6 indicate that, the higher the $\mathrm{Re}_{\text {in }}$ number, the longer the part of the model of the condensing heat exchanger that is inefficiently used for heat transfer due to convection in a larger inlet part of it.

The analysis showed that, in the case of water-vapor mass fraction $\approx 7 \%$ as the inlet water vapor flow rate was from $\approx 1.7$ to $\approx 3.1 \mathrm{~kg} / \mathrm{h}$, the total condensate flow rate was also small and the condensation efficiency was in the range between $\approx 15 \%$ and $26 \%$. When the condensable gas mass fraction was increased to $\approx 17 \%$, the inlet water vapor flow rate was almost two times higher and the total condensate flow rate was also about two times higher in comparison with the previous case. Due to this, the condensation efficiency was about 2.3-2.5 times higher and was in the range between $\approx 39 \%$ and $56 \%$.

\section{Conclusions}

After performing the analysis of the local water vapor condensation from biofuel flue gas along the model of the condensing heat exchanger (vertical tube) at different water-vapor mass fractions, $\operatorname{Re}_{\text {in }}$ numbers, and inlet flue gas temperatures, the following conclusions were drawn: 
- Performed analysis revealed the influence of inlet parameters on heat transfer processes occurring in condensing heat exchangers.

- The investigations of the local heat transfer along the tube (the model of the condensing heat exchanger) provided important findings related to the optimization of the operation of heat exchangers of such type.

- The investigations showed that, in some cases in the initial part of the condensing heat exchanger model, the heat from flue gas is recovered by convection. Only after that, a sharp increase is noticed in heat transfer due to water vapor condensation.

- The analysis showed that, in the case of water-vapor mass fraction $\approx 7 \%$, the condensation efficiency was in the range between $\approx 15 \%$ and $26 \%$. When the condensable gas mass fraction was increased until $\approx 17 \%$, the condensation efficiency was in the range between $\approx 39 \%$ and $56 \%$.

- To use the condensing heat exchangers efficiently, there is a need to adjust certain flue gas flow rate, temperature and humidity and other parameters in such a way that the condensation of water vapor would be from the beginning of the condensing heat exchanger.

Author Contributions: Conceptualization, R.P.; methodology, A.S. and P.P.; formal analysis, A.S. and V.K.; experimental investigation, V.K. and A.S.; writing_-original draft preparation, A.S. and V.K.; writing - review and editing, P.P. and R.P.; supervision, R.P. All authors have read and agreed to the published version of the manuscript.

Funding: This research was funded by Research council of Lithuania (LMTLT), grant number S-MIP-20-30.

Institutional Review Board Statement: Not applicable.

Informed Consent Statement: Not applicable.

Data Availability Statement: Not applicable.

Conflicts of Interest: The authors declare no conflict of interest.

\section{References}

1. Thulukkanam, K. Heat Exchanger Design Handbook, 2nd ed.; CRC Press: Boca Raton, FL, USA, 2013.

2. Kasurinen, S.; Jalava, P.I.; Tapanainen, M.; Uski, O.; Happo, M.S.; Mäki-Paakkanen, J.; Lamberg, H.; Koponen, H.; Nuutinen, I.; Kortelainen, M.; et al. Toxicological effects of particulate emissions-A comparison of oil and wood fuels in small- and medium-scale heating systems. Atmos. Environ. 2015, 103, 321-330. [CrossRef]

3. Survey of the Present State of Particle Precipitation Devices for Residential Biomass Combustion with a Nominal Capacity up to 50 KW in IEA Bioenergy Task32; Final Version; Institute for Process and Particle Engineering, Graz University of Technology: Graz, Austria, 2013. Available online: https:/ / www.bios-bioenergy.at/uploads/media/Filter-study-IEA-Dez-2011.pdf (accessed on 21 January 2021).

4. Che, D.; Liu, Y.; Gao, C. Evaluation of retrofitting a conventional natural gas fired boiler into a condensing boiler. Energy Convers. Manag. 2004, 45, 3251-3266. [CrossRef]

5. Satyavada, H.; Baldi, S. A novel modelling approach for condensing boilers based on hybrid dynamical systems. Machines 2016, 4, 10. [CrossRef]

6. Siddique, M.; Golay, M.W.; Kazimi, M.S. Local heat transfer coefficients for forced-convection condensation of steam in a vertical tube in the presence of a noncondensable gas. Nucl. Technol. 1993, 102, 386-402. [CrossRef]

7. Park, H.S.; No, H.C. A condensation experiment in the presence of noncondensables in a vertical tube of a passive containment cooling system and its assessment with RELAP5/MOD3.2. Nucl. Technol. 1999, 127, 160-169. [CrossRef]

8. Maheshwari, N.; Saha, D.; Sinha, R.; Aritomi, M. Investigation on condensation in presence of a noncondensable gas for a wide range of Reynolds number. Nucl. Eng. Des. 2004, 227, 219-238. [CrossRef]

9. Caruso, G.; Giannetti, F.; Naviglio, A. Experimental investigation on pure steam and steam-air mixture condensation inside tubes. Int. J. Heat Technol. 2012, 30, 77-84. [CrossRef]

10. Park, I.; Kim, S.-M.; Mudawar, I. Experimental measurement and modeling of downflow condensation in a circular tube. Int. J. Heat Mass Transf. 2013, 57, 567-581. [CrossRef]

11. Oh, S.; Revankar, S.T. Experimental and theoretical investigation of film condensation with noncondensable gas. Int. J. Heat Mass Transf. 2006, 49, 2523-2534. [CrossRef]

12. Lee, K.-Y.; Kim, M.H. Experimental and empirical study of steam condensation heat transfer with a noncondensable gas in a small-diameter vertical tube. Nucl. Eng. Des. 2008, 238, 207-216. [CrossRef]

13. Jia, L.; Peng, X.; Yan, Y.; Sun, J.; Li, X. Effects of water vapor condensation on the convection heat transfer of wet flue gas in a vertical tube. Int. J. Heat Mass Transf. 2001, 44, 4257-4265. [CrossRef] 
14. Delalić, N.; Ganić, E.; Džaferović, E. Experimental and numerical study on vapor condensation of wet flue gas in chimney. Defect Diffus. Forum 2008, 273, 119-125. [CrossRef]

15. Chantana, C.; Kumar, S. Experimental and theoretical investigation of air-steam condensation in a vertical tube at low inlet steam fractions. Appl. Therm. Eng. 2013, 54, 399-412. [CrossRef]

16. Shi, X.; Che, D.; Agnew, B.; Gao, J. An investigation of the performance of compact heat exchanger for latent heat recovery from exhaust flue gases. Int. J. Heat Mass Transf. 2011, 54, 606-615. [CrossRef]

17. Li, J.-D.; Saraireh, M.; Thorpe, G. Condensation of vapor in the presence of non-condensable gas in condensers. Int. J. Heat Mass Transf. 2011, 54, 4078-4089. [CrossRef]

18. Siddique, M. The Effects of Noncondensable Gases on Steam Condensation under Forced Convection Conditions. Ph.D. Thesis, Department of Nuclear Engineering, Massachusetts Institute of Technology, Cambridge, MA, USA, 1992.

19. Jeong, K.; Kessen, M.J.; Bilirgen, H.; Levy, E.K. Analytical modeling of water condensation in condensing heat exchanger. Int. J. Heat Mass Transf. 2010, 53, 2361-2368. [CrossRef]

20. Barford, N.C. Experimental Measurements: Precision, Error and Truth, 2nd ed.; John Willey \& Sons: Hoboken, NJ, USA, 1985.

21. American Meteorological Society. Available online: https://journals.ametsoc.org/doi/pdf/10.1175/BAMS-86-2-225 (accessed on 21 January 2021). 